\title{
Cari Denge Açısından Yenilenebilir Enerjinin Rolü: Avrupa Birliği Ülkeleri ve Türkiye İçin Panel Veri Analizi
}

\author{
Cem GÖKCE*
}

\author{
Gökhan DEMİRTAŞ**
}

\begin{abstract}
$\ddot{O} Z$
Bu çalışmanın amacı, yenilenebilir enerji tüketiminin cari denge üzerine etkisini panel veri yöntemi ile incelemektir. Bu amaçla 27 Avrupa Birliği ülkesi (Malta hariç) ve Türkiye'nin 1998-2015 dönemine ait verileri kullanılarak sabit etkiler ve rassal etkiler modelleri tahmin edilmiştir. Çalışmadaki ülkelerin çoğunluğu enerjide dışa bağımlılık oranı yüksek ve cari açık sorunu yaşayan ülkelerden oluşmaktadır. Çalışmanın sonuçlarına göre yenilenebilir enerji tüketimindeki oransal artış, cari denge üzerinde istatistiki olarak anlaml ve pozitif bir etkiye sahiptir. Buna ek olarak ampirik sonuçlar, enerjide dışa bağımlılık oranının cari denge üzerinde istatistiksel olarak anlamlı ve negatif bir etkiye sahip olduğunu göstermektedir. Bu sonuçlar, yenilenebilir enerji yatırımlarının, Avrupa Birliği ve Türkiye için cari açı sorununu çözmede önemli bir alternatif olduğu anlamına gelmektedir.
\end{abstract}

Anahtar Kelimeler: Yenilenebilir Enerji, Cari Açık, Panel Veri Analizi

JEL Sinıflandırması: Q21, F32, C23

\section{The Role of Renewable Energy in Terms of Current Account Balance: Panel Data Analysis for European Union Countries and Turkey}

\begin{abstract}
The aim of this paper is to examine the effect of renewable energy consumption on the current account balance by panel data method. For this purpose, fixed and random effects models are estimated using data over the period from 1998 to 2015 for 27 countries of European Union and Turkey. These countries are mostly composed of countries with high energy dependency rate and current account deficit problem. According to the estimation results, increasing in the rate of renewable energy consumption has a positive and significant impact on current account balance. In addition, the empirical results indicate that energy dependency rate has a negative and significant impact on current account balance. These results imply that investments in renewable energy are an important alternative to solve the current account deficit for the European Union countries and Turkey.
\end{abstract}

Key Words: Renewable Energy, Current Account Deficit, Panel Data Analysis

JEL Classification: : Q21, F32, C23

\section{GİRIŞ}

Enerji, ekonomiden siyasete çok boyutlu etkiye sahip bir konudur. Bir ekonomi açısından sıradan bir ara malı olmanın ötesinde enerji, üretim sürecinde emek ve sermaye gibi üretim faktörlerini tamamlayıcı bir faktördür. Enerji

\footnotetext{
${ }^{*}$ Dr. Öğr. Üyesi, Afyon Kocatepe Üniversitesi, İktisadi ve İdari Bilimler Fakültesi, İktisat Bölümü. cgokce@aku.edu.tr

*** Doç. Dr., , Afyon Kocatepe Üniversitesi, İktisadi ve İdari Bilimler Fakültesi, İktisat Bölümü. demirtas@aku.edu.tr
} 
ekonomisi literatüründe enerji tüketiminin üretim, büyüme ve işsizlik gibi birçok makroekonomik değişken üzerindeki etkisi incelenmektedir. Diğer yandan kişi başına enerji tüketimi, Dünya Bankası gibi birçok uluslararası kuruluş tarafından kalkınma göstergesi olarak kullanılmaktadır.

Avrupa Komisyonu tarafından 2013 yılında hazırlanan "Üye Devletlerin Enerji Bağımlılığı: Gösterge Temelli Bir Değerlendirme" başlıklı raporda Avrupa Birliği (AB) ülkelerinin farklı seviyelerde fakat yüksek oranda enerji bağımlılığı olduğu belirtilmektedir. Bu durum, üye ülkeleri enerji fiyatlarındaki şoklara ve enerji arzındaki aksamalara karşı savunmasız bir duruma getirmektedir. Bu şoklar, üye ülke ekonomilerinde rekabet ve GSYH kayıplarına, enflasyon baskısına ve ticaret dengesinde bozulmalara neden olmaktadır. Enerji arz güvenliği, ithalat bağımlılığı, enerji ithalatı yapılan coğrafyanın çeşitliliği (bir ülkeye bağımlı olma riski) ve enerji kaynaklarının çeşitlendirilmesi gibi hususları içermektedir. Bu göstergelerdeki bozulmalar, bir ülke ekonomisinin istikrarsızlaşmasına neden olabilmektedir. Enerji ticaret dengesindeki açıklar, cari işlemler dengesizliklerine neden olabilmekte ve bu kanalla ülkelerin rekabet düzeyi olumsuz etkilenebilmektedir.

Raporun devamında yenilenebilir enerji üretimindeki artışın elektrik üretimi, 1sıtma ve soğutma ihtiyaçlarının giderilmesi ve ulaşım konularında enerji (arz) güvenliğini artırmanın en etkili yollarından birisi olduğu vurgulanmaktadır. Yenilenebilir enerji kaynakları, ithal fosil yakıtlara olan bağımlılık ve kıtlıkla ilgili riskleri azaltır. Büyük oranda yurtiçinde üretilen yenilenebilir enerji, üye ülkelerin enerji arz sıkıntısı ve fiyat şoklarından korunmasına ve enerji ticaret açı̆̆ını azaltmasına katkıda bulunur.

Enerji ticaret dengesi, bir ekonominin diş dengesizlikleri için genellikle kabul gören ana göstergelerden biridir. Bu nedenle enerji kaynaklarına sahip olmayan ülkeler için enerji ticaret dengesindeki açık, cari işlemler dengesinin arka planındaki nedenlerden birisidir. Ancak cari dengedeki her değişimin nedenini hem ülkeler açısından hem de periyot açısından sadece enerji ticaret dengesine bağlamak mümkün değildir. Makroekonomik dengesizliklerle olan bağlantısı nedeniyle sadece bir ülkenin enerji ticaret dengesi belirli bir yıl veya dönem için değerlendirilmemeli aynı zamanda enerji ticareti açığının etkilerinin kalıcı olup olmadığı üzerine analiz yapılmalıdır.

Yukarıda belirtilen noktalardan hareketle bu çalışmanın amacı yenilenebilir enerji tüketiminin cari denge üzerine etkisini ampirik açıdan incelemektir. Bu amaçla AB'den 27 ülke (Malta hariç) ve Türkiye'nin 1998-2015 dönemlerine ilişkin verisi kullanılarak panel veri yöntemiyle oluşturulan modellerde sabit etkiler ve rassal etkiler modeli tahmin için kullanılmıştır. Örneklemde yer alan ülkelerin büyük bir çoğunluğu enerji sektöründe dişa bağımlı ülkelerden oluşmaktadır. Ayrıca örneklemde yer alan 21 ülke belirtilen dönemde cari açık vermiştir. $\mathrm{Bu}$ iki nokta birlikte düşünüldügünde yenilenebilir enerji kaynaklarının cari açık üzerindeki etkisini incelemek için AB ülkeleri ve Türkiye örneklem olarak seçilmiştir. Bu çalışmanın bir diğer özgün katkısı, yenilenebilir enerji tüketiminin cari denge üzerine etkisini ele alan bir ampirik çalışmaya 
rastlanılmamasıdır. $\mathrm{Bu}$ çalışma, cari işlemler açığının belirleyicisi olarak yenilenebilir enerji tüketimini ele almaktadır.

\section{TEORIKK ARKA PLAN}

Çalışmanın teorik altyapısını oluşturabilmek için yenilenebilir enerjinin neden önemli olduğu sorusuna cevap vermek gerekir. Bu cevabın ardından cari açık sorunu yaşayan ülkeler için yenilenebilir enerji üretiminin neden önemli olduğu üzerinde durulacaktır. Yenilenebilir enerji arzının artması, enerji arz güvenliğini artırması ve enerjide dışa bağımlılı̆̆ı azaltması bakımından bir ekonomi için önemlidir. Enerji güvenliği kavramı, ilk çıktığı dönemlerde petrol ve uluslararası enerji ticaretine odaklanmaktadır. (Pascual ve Elkind, 2010) Günümüzde ise bu kavram, enerji ekonomisi yönetimi başlığı altında jeopolitik hassasiyetler, iklim değişikliği ve enerji bağımsızlığı gibi birçok kavrama odaklanmaktadır. Hogan v.d. (2007:29), enerji güvenliğini, "genellikle ekonomik büyümeyi sürdürmek için makul fiyatlarla yeterli ve güvenilir enerji kaynaklarının sağlanması" şeklinde tanımlamıştır. Enerji arzının yeterli, uygun fiyatlarla, kesintisiz, kaliteli ve çevreye zararsız bir şekilde gerçekleştirilmesine "enerji arz güvenliği” ismi verilmektedir.

Enerji arz güvenliğini sağlamanın çeşitli stratejileri bulunmaktadır. $\mathrm{Bu}$ stratejilerin büyük bir kısmı tüm ülkeler için ortakken bazıları ise ülkelere ve bölgelere göre küçük farklılıklar göstermektedir. Örneğin Türkiye için petrol ve doğalgaz boru hatları, enerji arz güvenliğini sağlama stratejilerinden biri sayılırken AB ülkeleri için böyle bir strateji söz konusu değildir. UNESCAP (2008:205) raporunda bu konuyla ilgili genel stratejiler şu şekilde açıklanmaktadır: (1) Enerji verimliliği ve tasarrufunu artırılması, (2) enerji arz kaynaklarının çeşitlendirilmesi, (3) enerji altyapı yatırımlarının artırılması, (4) yenilenebilir enerji kaynaklarına yönelinmesi, (5) Ar\&Ge yoluyla yenilik ve rekabeti teşvik edilmesi, (6) enerji fiyat dalgalanmalarına karşı kırılganlığın azaltılması. Görüldüğü gibi bu raporda yenilenebilir enerji arzı, arz güvenliğini sağlama stratejilerinden birisidir. Benzer şekilde Zhang v.d. (2010) ve Umbach (2010), yenilenebilir enerji tüketiminin arttırılmasını, enerji arz güvenliğini sağlamada en önemli stratejilerden birisi olarak tanımlamaktadır.

Çalışkan (2009:308), Türkiye için enerji arz güvenliğgi stratejilerini belirtirken fosil yakıtların depolanması ve nükleer enerji alternatifinin değerlendirilmesi, kaynak ve ülke çeşitliliğinin sağlanmasına ek olarak yerli enerji kaynakları arzının artırılmasına değinmektedir. $\mathrm{Bu}$ açıdan bakıldığında yenilenebilir enerji kaynakları aynı zamanda yerli enerji kaynaklarından oluştuğu için fosil kaynakların güçlü ikamesini oluşturmaktadır. Bu noktadan hareketle tükettiği enerjiyi kendi üretebilen ülkelerin enerji arz güvenliği artmaktadır. Bu durum, ayrıca enerjide dışa bağımlılık oranını da azaltmaktadır. Yenilenebilir enerjinin yerli ve tükenmez bir kaynak olduğu gözden kaçırılmamalıdır.

Enerji sektörü açısından dışa bağımlılığı yüksek ekonomilerde ön plana çıkan makroekonomik problemlerden biri cari açıktır. Bu açı̆̆ın temel nedenlerinden bir tanesi mal ticareti kaleminde ithalatın ihracata göre yüksek olmasıdır. Bunun $\mathrm{AB}$ ve Türkiye için en önemli nedeni enerji ithalatıdır. $\mathrm{AB}$ ülkelerinin büyük bir çoğunluğunda da enerji ticareti dengesizliklerinin cari 
işlemler dengesi üzerinde olumsuz etkisi bulunmaktadır. (European Commission, 2013:42) Türkiye ekonomisinde de cari işlemler açığının büyük ölçüde enerji ithalatına bağlı olduğunu ifade eden çalışmalar bulunmaktadır. (Öztürk, 2014:11 ve Murat v.d., 2014:978) Benzer bir tespiti yapan Bölük (2013:153), özellikle petroldeki dışa bağımlılık açısından biyo-etanol gibi biyo-yakıt üretiminin önemine dikkat çekmektedir.

Zengin yer altı kaynaklara sahip olmayan ekonomiler açısından bu problemin en önemli çözüm önerilerinden birisi yenilenebilir enerji kaynaklarıdır. Bu kaynaklarının tüketimindeki artış, enerji ithalatının önüne geçerek enerjide dışa bağımlılı̆̆ı azaltır ya da dışa bağımlılığın artmasını önler. Enerji ithalatçısı ülkelerde yenilenebilir enerjinin toplam enerji tüketimi içerisindeki payının artması, ülkenin ödemeler bilançosuna olumlu etkide bulunur. Bununla birlikte yenilenebilir enerji tüketiminin arttırılması ülkeden döviz çıkışını da engellemektedir.

Enerji sektöründe dışa bağımlı olmayan ve enerji kaynaklarının sahibi konumunda bulunan ekonomilerde de enerji sektörü, ekonomik büyüme ve kalkınmayı etkileyen sektörlerden birisidir. Örneğin Stern (2004:48) çalışmasında ABD için GSYH ile enerji tüketimi arasında bir bağ olduğunu ifade etmiştir. Benzer şekilde Apergis ve Payne (2010: 656), 20 OECD ülkesi için ve Bölük ve Mert (2014:444) yenilenebilir enerji tüketimi ile ekonomik büyüme arasında bir ilişki olduğu sonucuna ulaşmıştır.

\section{YENILENEBİLIR ENERJIDE GELIŞMELER}

Yenilenebilir enerji, enerji arz güvenliğini sağlama stratejilerinden biri olduğu için $\mathrm{AB}$, bu konuya çok uzun yıllar önce dikkat çekmiştir. Enerji güvenliği kavramı, 1970'lerde yaşanan petrol krizlerinden sonra sıklıkla kullanılmaya başlanmıştır. AB, 1973 ve 1979 petrol krizlerinden sonra fosil kaynaklara alternatif bulma çabasına girmesine rağmen 80'li yıllarda somut gelişmeler olmamıştır. $\mathrm{Bu}$ bağlamda somut gelişmeler, 1990'l1 y1llarda gerçekleşmiştir. AB'nin enerji politikalarını ortaya koyan temel belgelerden birisi olan "Yeşil Kitap" adlı belge 1996 yılında yayınlanmaya başlamıştır. Yeşil Kitap, aynı zamanda AB'nin yenilenebilir enerji tüketimine verdiği önemi de ortaya koymaktadır. Bununla birlikte AB, 1990'lı yılların başlarından itibaren "SAVE" gibi programlarla enerji arz güvenliğini sağlama ve enerji bağımlılığını düşürmeye yönelik politikaları yoğun bir şekilde uygulamıştır. Bu politikaların somut örneklerinden birisi olan "Energy Charter Treaty" başlıklı anlaşma AB ülkelerinin yanında Türkiye'nin de yer aldığı toplam 50 ülke tarafından 1994 yılında imzalanmıştır. Bu anlaşma ve SAVE programının temel amacı, enerji arz güvenliğinin sağlanmasıdır. Ayrıca enerjinin verimli kullanılması, enerji sektörünün serbestleştirilmesi, enerji yatırımlarının teşviki gibi politikalara da önem verilmiştir.

Dünyada yenilenebilir enerji tüketimi her geçen gün artmaktadır. Bu artış, enerji sektöründe dışa bağımlı ülkelerin dışa bağımlılığını azaltmasa bile artmasına engel olmaktadır. AB ve Türkiye'deki yenilenebilir enerji tüketiminin seyri Grafik 1'de gösterilmiştir. 1998-2014 periyodunda yenilenebilir enerjinin toplam enerji tüketimi içerisindeki payının görüldügü bu grafikte Türkiye ve $\mathrm{AB}$ ülkeleri için 
birbirinin tersi bir eğilim olduğu açıkça görülmektedir. 1998 yılında $\mathrm{AB}$ için oran \%7-8 seviyelerinde iken 2014 yılında bu oran \%16'nın üzerine çıkmıştır. Türkiye'de ise 1998 yılında oran \%21'in üzerinde iken 2014 yılında \%12'nin altına inmiştir. Özetle $\mathrm{AB}$ bu süreçte yenilenebilir enerjinin payını hızla arttırırken Türkiye'de yenilenebilir enerjinin payı azalmıştır. Buradaki durum diğer verilerle birlikte incelendiğinde, 1998-2014 periyodunda Türkiye'de yenilenebilir enerji tüketimi artmasına rağmen Türkiye'nin enerji talebi daha hızlı arttığı için yenilenebilir enerji tüketimindeki bu artışın enerji talebindeki artışa ayak uyduramadığ görülmüştür. $A B$ ve Türkiye'yi incelerken gözden kaçırılmaması gereken en önemli noktalardan birisi gelişmişlik farklılıklarıdır. Türkiye'nin gelişmekte olan bir ülke olarak enerji talebi her geçen yıl hızla artmaktadır. AB ülkelerinde ise durum biraz daha farklıdır. $\mathrm{AB}$ ülkelerinin büyük bir çoğunluğu gelişmiş ülkelerden oluştuğu için $\mathrm{AB}$ 'nin toplam enerji talebi Türkiye kadar hızlı artmamaktadir.

Grafik 1: Yenilenebilir Enerji Tüketiminin Toplam Enerji Tüketimi İçindeki Payı (\%)

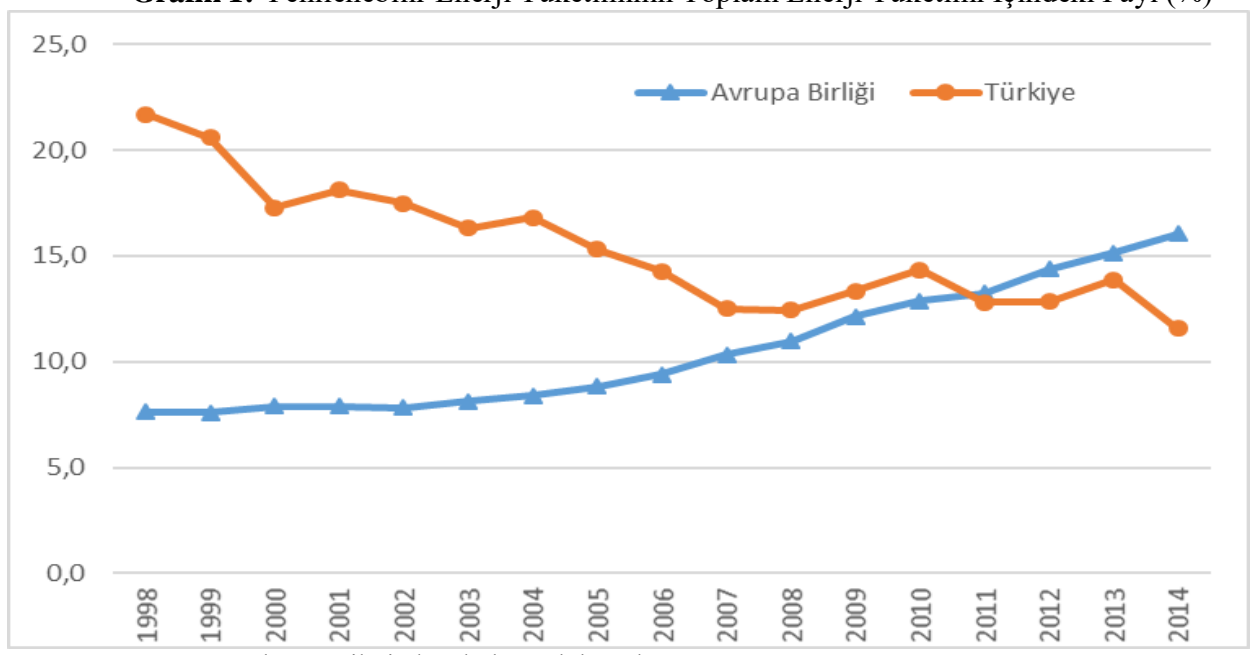

Kaynak: Dünya Bankası verilerinden derlenerek hazırlanmıştır.

Grafik 2'de Türkiye ve AB-28'in 1990-2015 periyodundaki enerji bağımlık oranları yer almaktadır. Grafik 1 ile birlikte incelendiğinde AB'nin yenilenebilir enerji politikalarının AB-28'in enerji bağımlılığı üzerine oldukça önemli etkisi olduğu görülmektedir. 1990'da AB'nin enerji bağımlılık oranı \%44 iken Türkiye'de bu oran $\% 52$ seviyelerindedir. Süreç içerisinde Türkiye'nin enerji bağımlılığı hızla artarken $\mathrm{AB}$ aldığı önlemler sayesinde bu artışı sınırlı tutmuştur. 2015 yılında AB'nin enerji bağımlılık oranı \%54 seviyesinde iken Türkiye'de bu oran \%77'nin üzerine çıkmıştır. 
Grafik 2. AB-28 ve Türkiye'nin Enerji Bağımlılıkları (\%)

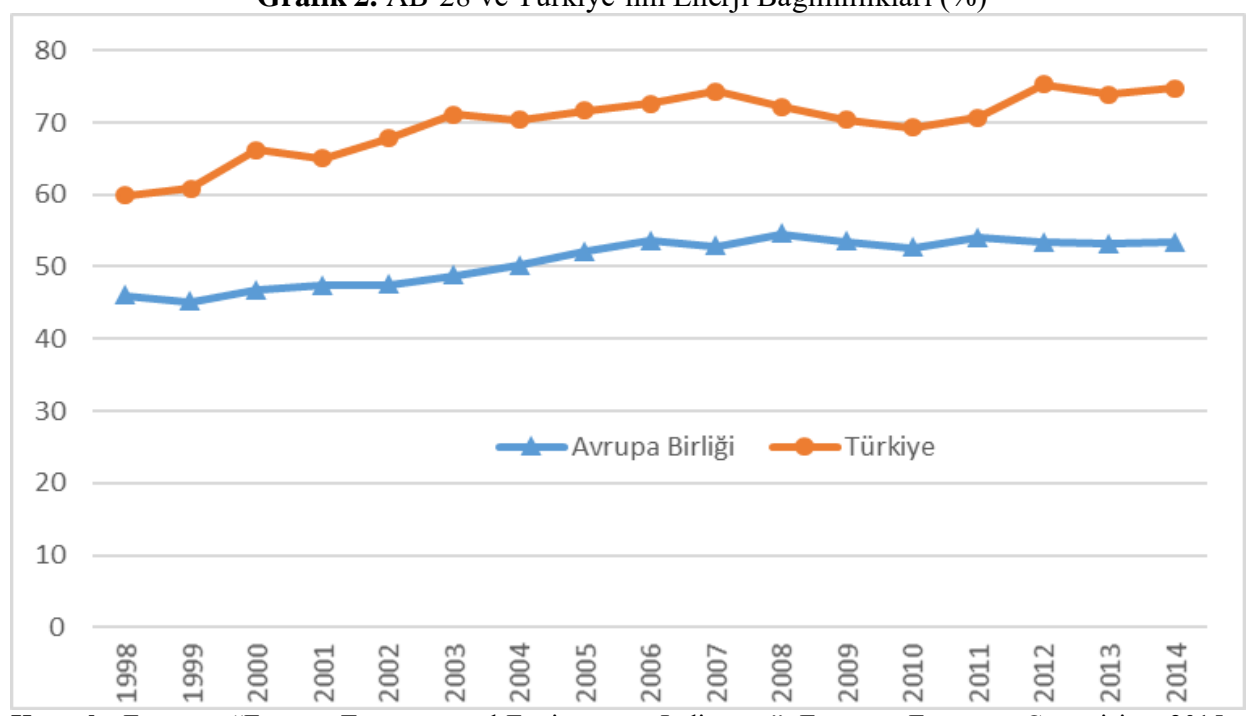

Kaynak: Eurostat, "Energy, Transport and Environment Indicators", Eurostat, European Commision, 2015, verilerinden derlenerek hazırlanmıştır.

Grafik 1 ve 2'den çıkarılacak en önemli sonuç, yenilenebilir enerji yatırımlarının ve yenilenebilir enerji tüketiminin ülkelerin enerjide dışa bağımlılığını önemli derecede etkilediğidir. $\mathrm{AB}$, enerji arz güvenliğini artırmak ve enerji bağımlılığını azaltmak prensipleri çerçevesinde 1990'lı yılların başlarından itibaren yenilenebilir enerji politikalarını oluşturmuş ve yenilenebilir enerji yatırımlarının hızla artması için yukarıda belirtilen çeşitli stratejileri geliştirmiştir. Türkiye'de ise yenilenebilir enerjiye yönelik en somut belge olan yenilenebilir enerji kanunu ancak 2005 yılında yürürlüğe girmiştir.

Geçmişte yenilenebilir enerji kaynaklarının toplam birincil enerji tüketimi içerisinde önemli bir payı olmasa da her geçen gün artan bir öneme sahiptir. IEA (2017) verilerine göre 1973 yllında yenilenebilir enerji arz1 756,5 Mtep iken bu rakamın 2015 yılında 1869,6 Mtep'e ulaştı̆g görülmektedir. Günümüzde yenilenebilir enerji, Dünya'da en hızlı büyüyen enerji kaynağıdır. Gelecekte de bu artışın devam edeceği, 2040 yılına kadar yıllık artış oranının ortalama $\% 2,8$ olacağı öngörülmektedir. (US Energy Information Administration, 2017:20)

\section{LITERATÜR TARAMASI}

Literatürde yenilenebilir enerji tüketiminin ekonomik büyüme, istihdam, dış ticaret ve gelir gibi çeşitli makroekonomik büyüklükler üzerine etkilerini inceleyen çalışmalar olmasına rağmen yenilenebilir enerji tüketiminin cari işlemler dengesi üzerine etkisini doğrudan ele alan ampirik çalışmaya rastlanmamıştır. Bununla birlikte yenilenebilir enerji tüketiminin cari açık üzerine etkisini dolaylı olarak ele alan bazı çalışmalar bulunmaktadır. Bu çalışmalardan birisi Vaona (2016) tarafından yapılmıştır. Çalışmada yenilenebilir enerji üretimi ile ithalat arasındaki ilişki, ithalat talep denklemi çerçevesinde incelenmiştir. Yenilenebilir enerji üretimi ve ithalat arasındaki bağlantıyı araştıran bu çalışmada 26 ülkenin farklı periyottaki verisi için panel GMM yöntemi kullanılmıştır. Bu çalışmanın 
sonucunda yenilenebilir enerji üretiminin ithalat büyümesini azalttığı sonucuna ulaşılmıştır. Çalışmanın sonuçları, yenilenebilir enerji üretiminin dışa bağımlılığı azalttığına dair hipotezi desteklemektedir.

Çalışmanın önemli sonuçlarından bir diğeri ise yenilenebilir enerji üretiminin genel ekonomik katkısıdır. Bu katkı iki yolla gerçekleşir. Birincisi yenilenebilir enerji üretimi ile birlikte daha az kullanılan nükleer ve fosil kaynaklar sonucu sağlık ve çevresel dışsallıklarla ilgili katkıdır. İkincisi ise dışa bağımlılık ve borçlanmanın azaltılması ile ilgili katkıdır.

Bir diğer çalışmada Jebli ve Youssef (2015), 69 ülkenin 1980-2010 dönemine ilişkin verisini kullanmıştır. Panel eş-bütünleşme tekniğinin uygulandığ1 bu çalışmada yenilenebilir enerji tüketimi, yenilenemez enerji tüketimi, çıktı ve dış ticaret arasındaki ilişki incelenmiştir. Çalışmanın kısa dönemli sonucuna göre yenilenebilir enerji tüketiminden dış ticarete doğru tek yönlü nedensellik ilişkisi tespit edilmiştir. Uzun dönemde ise yenilenebilir enerji ile diş ticaret (ihracat ve ithalat) arasında çift yönlü nedensellik ilişkisi tespit edilmiştir. Ayrıca çalışmada yenilenebilir enerji tüketimi, yenilenemez enerji tüketimi ve dış ticaretin ekonomik büyüme üzerinde pozitif ve istatistiksel olarak anlamlı etkisi olduğu sonucuna varılmıştır. Buna karşılık Chien ve $\mathrm{Hu}$ (2008), yenilenebilir enerji tüketiminin dış ticaret dengesi üzerine istatistiksel olarak anlamlı bir etkisinin olmadığı sonucuna ulaşmıştır. Çalışmada 116 ülkenin 2003 yılı verisini yapısal eşitlik modelinde kullanan yazarlara göre bu sonuç, yenilenebilir enerji tüketimindeki artışın herhangi bir ithal ikamesi etkisinin olmadığını göstermektedir.

Yenilenebilir enerjinin farklı makroekonomik değişkenler üzerine etkisini ele alan ampirik çalışmalara ilişkin detaylı bilgiler Tablo 1'de yer almaktadır. Lehr v.d. (2012), yenilenebilir enerji tüketimi artışının istihdamı artırdığı; Chien ve Hu (2008), yenilenebilir enerji tüketimi ile sermaye oluşumu arasında pozitif bir ilişki olduğu; Bhattacharya v.d. (2016), 38 ülkenin çoğunluğunda yenilenebilir enerji tüketiminin ekonomik çıktı üzerine pozitif etkisi olduğu sonucuna ulaşmıştır. Son olarak Salim ve Rafiq (2012) ise Brezilya, Çin, Hindistan, Endonezya, Filipinler ve Türkiye üzerine yaptığı çalışmasında yenilenebilir enerji tüketimi ile GSYİH arasında iki yönlü nedensellik ilişkisi tespit etmiştir.

Tablo 1. Yenilenebilir Enerjinin Çeşitli Makro-Ekonomik Değişkenler Üzerine Etkisi

İle İlgili Literatür Araştırması

\begin{tabular}{|l|l|l|l|}
\hline Yazar(lar) & $\begin{array}{l}\text { Örneklem } \\
\text { Dönem }\end{array}$ & $\begin{array}{l}\text { Ekonometrik } \\
\text { Yaklaşım }\end{array}$ & Sonuç \\
\hline $\begin{array}{l}\text { Bento ve } \\
\text { Moutinho } \\
\text { (2016) }\end{array}$ & İtya / 1960-2011 & $\begin{array}{l}\text { Zaman Serisi, } \\
\text { Eş-bütünleşme } \\
\text { ve Nedensellik }\end{array}$ & $\begin{array}{l}\text { Kişi başına çıktı miktarından yenilenebilir } \\
\text { elektrik üretimine doğru tek yönlü bir } \\
\text { nedensellik ilişkisi mevcuttur. }\end{array}$ \\
\hline Lehr v.d. (2012) & $\begin{array}{l}\text { Almanya / 1991- } \\
2008\end{array}$ & $\begin{array}{l}\text { PANTA RHEI } \\
\text { modeli }\end{array}$ & $\begin{array}{l}\text { Yenilenebilir enerji ile istihdam arasında pozitif } \\
\text { bir ilişki söz konusudur. }\end{array}$ \\
\hline $\begin{array}{l}\text { Çağlayan-Akay } \\
\text { v.d. (2015) }\end{array}$ & $\begin{array}{l}9 \text { MENA ülkesi / } \\
1988-2010\end{array}$ & $\begin{array}{l}\text { Panel VAR ve } \\
\text { GMM }\end{array}$ & $\begin{array}{l}\text { Ekonomik büyüme ve yenilenebilir enerji } \\
\text { tüketimi arasında çift yönlü nedensellik ilişkisi } \\
\text { vardır. }\end{array}$ \\
\hline $\begin{array}{l}\text { Apergis ve } \\
\text { Danuletiu } \\
\text { (2014) }\end{array}$ & $\begin{array}{l}\text { S0 ülke / 1990- } \\
2012\end{array}$ & $\begin{array}{l}\text { Panel Veri } \\
\text { Analizi }\end{array}$ & $\begin{array}{l}\text { Yenilenebilir enerji, ekonomik büyümenin } \\
\text { belirleyicilerindendir. Ayrıca ekonomik } \\
\text { büyüme daha fazla yenilenebilir enerji } \\
\text { tüketimini teşvik eder. }\end{array}$ \\
\hline Tiwari (2011) & $\begin{array}{l}\text { Hindistan / 1960- } \\
2009\end{array}$ & $\begin{array}{l}\text { Yapısal VAR } \\
\text { Analizi }\end{array}$ & $\begin{array}{l}\text { Yenilenebilir enerji tüketimi üzerindeki pozitif } \\
\text { bir şok GSYH'yi artırır. Yenilenebilir enerji }\end{array}$ \\
\hline
\end{tabular}


Cem Gökce \& Gökhan Demirtaş / Cari Denge Açısından Yenilenebilir Enerjinin Rolü: Avrupa Birliği Ülkeleri ve Türkiye İçin Panel Veri Analizi

\begin{tabular}{|c|c|c|c|}
\hline & & & $\begin{array}{l}\text { tüketiminin payı GSYH'yi önemli derecede } \\
\text { açıklamaktadır. }\end{array}$ \\
\hline $\begin{array}{l}\text { Bhattacharya } \\
\text { v.d. }(2016)\end{array}$ & $\begin{array}{l}38 \text { ülke / 1991- } \\
2012\end{array}$ & $\begin{array}{l}\text { Panel Veri } \\
\text { Analizi }\end{array}$ & $\begin{array}{l}\text { Uzun dönemli sonuçlara göre; seçilen ülkelerin } \\
\text { \%57'sinde, yenilenebilir enerji tüketiminin } \\
\text { ekonomik çıktı üzerinde pozitif etkisi } \\
\text { mevcuttur. }\end{array}$ \\
\hline $\begin{array}{l}\text { Salim ve Rafiq } \\
\text { (2012) }\end{array}$ & $\begin{array}{l}\text { Brezilya, Çin, } \\
\text { Hindistan, } \\
\text { Endonezya, } \\
\text { Filipinler, Türkiye } \\
\text { / 1980-2006 }\end{array}$ & $\begin{array}{l}\text { FMOLS, } \\
\text { DOLS }\end{array}$ & $\begin{array}{l}\text { Uzun dönemde yenilenebilir enerji tüketimi } \\
\text { gelir tarafindan belirlenmektedir. Kısa dönemde } \\
\text { yenilenebilir enerji ile gelir arasında çift yönlü } \\
\text { bir nedensellik ilişkisi mevcuttur. }\end{array}$ \\
\hline Fang (2011) & Çin / 1978-2008 & MOLS & $\begin{array}{l}\text { Yenilenebilir enerji tüketimindeki \%1'lik bir } \\
\text { artış reel GSYH'yi \% 0,120 ve kişi başına } \\
\text { GSYH'yi \%0,162 artırır. }\end{array}$ \\
\hline $\begin{array}{l}\text { Sadorsky } \\
(2009)\end{array}$ & $\begin{array}{l}18 \text { gelişmekte olan } \\
\text { ülke / 1994-2003 }\end{array}$ & $\begin{array}{l}\text { Panel Eş- } \\
\text { bütünleşme }\end{array}$ & $\begin{array}{l}\text { Uzun dönemde kişi başına reel gelirdeki \%1'lik } \\
\text { bir artış, gelişmekte olan ülkelerde kişi başına } \\
\text { yenilenebilir enerji tüketimini yaklaşı \% } \% 3,5 \\
\text { artırır. }\end{array}$ \\
\hline
\end{tabular}

\section{VERİ SETİ VE YÖNTEM}

Çalışmada panel veri yöntemi kullanılmıştır. Panel veri yapısı gereği hem birim $(\mathrm{N})$ hem de zaman (T) boyutunu içermesi açısından önemli bir avantaja sahiptir. Bu çalışmada panel verinin boyutu orta büyüklüktedir. Ayrıca birim sayısı, dönem sayısından görece büyük $(\mathrm{N}>\mathrm{T})$ ve $\mathrm{T}$ değeri görece az sayıdadır. Panel veri analizinde Klasik En Küçük Kareler (OLS), Rassal Etkiler (RE) ve Sabit Etkiler (FE) olmak üzere üç farklı tahmin modeli arasında seçim yapılması gerekmektedir. En küçük kareler yöntemi (OLS), spesifik birimlere ait etkilerin olmadığı göz önünde bulundurularak havuzlanmış verilerle açıklayıcı değişkenlerin, bağımlı değişken üzerindeki etkilerini araştıran modeldir. Panel veriler yapısı gereği, her bir birime ait farklı kesit katsayıları içerebilmektedir. Her birime ait sabit kesit katsayılarının tahmin edilmesinde FE Modeli kullanılırken her bir birime ait katsayıların bağımsız tesadüfî değişkenler olarak ele alındığı tahminlerde ise RE modelleri tercih edilmektedir. (Greene, 2012; Kenedy, 2006; Baltagi, 2005; Arellano, 2003; Wooldridge, 2002)

Uygulamada yer alan modellerin tahmininde hangi yöntemlerin kullanılacağına dair temelde üç belirleme testi bulunmaktadır. İlki (1) numaralı denklemde yer alan OLS modelinin mi yoksa FE modelinin mi kullanılacağına karar vermek amacıyla kullanılan F (Fischer ) testidir. Bu testin boş hipotezi, OLS modelinin; alternatif hipotezi ise FE modelinin kullanılacağını ifade etmektedir.

$$
F=\frac{\frac{R S S_{r}-R S S_{u r}}{N-1}}{\frac{R S S_{u r}}{N T-N-K}} \sim F_{N-1, N(T-1)-K}
$$

Model belirlemek için yapılan ikinci test, (2) numaralı denklemle gösterilen LM testidir. Bu test OLS modeli ile RE modeli arasında tercih yapmak için kullanılmaktadır. LM testinin boş hipotezi, OLS modelinin; alternatif hipotezi ise RE modelinin tercih edileceğini göstermektedir. 


$$
L M_{\mu}=\frac{N T}{2(T-1)}\left[\frac{\sum_{i=1}^{N}\left[\sum_{t=1}^{T} \hat{\varepsilon}_{i t}\right]}{\sum_{i=1}^{N} \sum_{t=1}^{T} \hat{\varepsilon}_{i t}^{2}}\right] \sim \chi_{1}^{2}
$$

Model belirlemek amaciyla yapılan son test (3) numaralı denklemle gösterilen Hausman Sinamasıdır. Bu sınama, RE modelinin mi yoksa FE modelinin mi kullanılacağına cevap vermektedir. Hausman sınamasının boş hipotezi, RE modelinin; alternatif hipotezi ise FE modelinin kullanılacağını ifade eder.

$$
W=\frac{\left(\hat{\beta}_{F E}-\hat{\beta}_{R E}\right)^{2}}{\operatorname{Var}\left[\hat{\beta}_{F E}\right]-\operatorname{Var}\left[\hat{\beta}_{R E}\right]} \sim \chi_{K}^{2}
$$

Çalışmanın modeli aşağıda yer alan (4) numaralı denklemde gösterilmiştir. Belirtilen modeldeki değişkenler cari açı̆̆ın belirleyicileri ile ilgili Freund (2005), Uz (2010), Calderon vd. (2002) tarafından yapılan çalışmalardan esinlenilerek belirlenmiştir. Bu modelde cari dengeyi belirleyen değişkenler şu şekilde organize edilebilir: İlk olarak cari dengeyi belirleyen faktörler, ekonomik büyüme, döviz kuru ve tasarruflar gibi makroekonomik değişkenlerden oluşmaktadır. Son olarak çalışmanın amacına yönelik olarak yenilenebilir enerji ve enerji ithalatı değişkenleri açılayıcı değişken olarak modelde yer almaktadır.

Aşağıda yer alan denklemde gösterilen modelin bağımlı değişkeni olan CD, cari dengenin GSYH içindeki payını göstermektedir. Modelde yer alan açıklayıcı değişkenler ise YET, toplam enerji tüketiminin yüzdesi olarak yenilenebilir enerji tüketimini; BUY, GSYH'deki yıllık büyüme hızını; REDK, reel efektif döviz kuru endeksini (2010 yılı baz alınarak); TAS, tasarrufların GSYH'ye oranı; EDA, enerji tüketiminin yüzdesi olarak enerji ithalatını ifade etmektedir. Çalışmada cari dengeyi belirleyen faktörler analiz edilirken kullanılan değişkenlere ilişkin veriler Dünya Bankası tarafından oluşturulan Dünya Kalkınma Göstergeleri veri tabanından alınmıştır.

$$
\begin{gathered}
C D_{i t}=\alpha_{i t}+\beta_{1} Y E T_{i t}+\beta_{2} B U Y_{i t}+\beta_{3} R E D K_{i t}+\beta_{4} T A S_{i t}+\beta_{5} E D A_{i t} \\
+\varepsilon_{i t}
\end{gathered}
$$

Yukarıda verilen model, $27 \mathrm{AB}$ ülkesi ve aday ülke olarak Türkiye için oluşturulan örneklem için 1998-2015 dönemine ait panel veriler kullanılarak tahmin edilmiştir. AB ülkelerinden sadece Malta, yeterli verisi olmadığından modele dahil edilmemiştir. Çalışmada kullanılan panel veri yöntemi, yapısı nedeniyle her ülkeye ait bütün zamanların gözlemlenmiş olması gereken dengeli panel veri yöntemidir. Bir başka deyişle herhangi bir ülkenin belirtilen yıllar için gözlemlenemeyen değeri bulunmamaktadır. Çalışmada kullanılan modeller, yenilenebilir enerjinin cari denge üzerine etkisini incelemenin yanı sıra cari dengeyi belirleyen diğer faktörleri de ele almaktadır.

\section{AMPIRİK SONUÇLAR}

Çalışmada kullanılan değişkenlere ilişkin tanımlayıcı istatistikler Ek-1'de ve korelasyon matrisi Ek-2'te yer almaktadır. Değişen varyans ve otokorelasyon sorununun olmaması, doğrusal regresyon modellerinde yer alan temel 
varsayımlardır. Belirtilen varsayımlardan sapmaların olması durumunda panel veri yönteminde FGLS (Feasible Generalized Least Square - Uygulanabilir Genelleştirilmiş En Küçük Karaler Yöntemi) tahmincisi kullanılmaktadır. (Grene, 2012) Uygulama bölümünde yer alan modellerde değişen varyans ve otokorelasyon sorunu olması nedeniyle FGLS tahmincisi kullanılmıştır.

Çalışmanın amacına uygun bir şekilde oluşturulan beş farklı modele ilişkin sonuçlar Tablo 2'de yer almaktadır. Model belirlemek için yapılan F ve LM testleriyle Hausman sınamasının sonuçları 5 model için de \%1 düzeyinde istatistiksel olarak anlamlıdır. Belirtilen model belirleme testlerinin sonuçları, Tablo 2'de yer alan modeller için FE model tahmininin uygun olduğunu göstermektedir. Tahmin sonuçları değerlendirildiğinde 5 numaralı model, tüm değişkenleri içermesi ve katsayıların anlamlı olması nedeniyle yorumlamak amacıyla tercih edilmiştir.

Tablo 2. Cari Dengenin Belirleyicileri Üzerine Uygulama

\begin{tabular}{|c|c|c|c|c|c|}
\hline \multicolumn{6}{|c|}{ Bağımlı Değişken: CD (Cari Denge); Örneklem: 28 Ülke; Dönem: 1998-2015 } \\
\hline Değişkeler & $\begin{array}{l}\text { Model } 1 \\
\text { FE }\end{array}$ & $\begin{array}{c}\text { Model } 2 \\
\text { FE }\end{array}$ & $\begin{array}{c}\text { Model } 3 \\
\text { FE }\end{array}$ & $\begin{array}{c}\text { Model } 4 \\
\text { FE }\end{array}$ & $\begin{array}{c}\text { Model } 5 \\
\text { FE }\end{array}$ \\
\hline Sabit Terim & $\begin{array}{c}-7,461 \\
(-15,89)^{\mathrm{a}}\end{array}$ & $\begin{array}{c}-6,889 \\
(-12,83)^{\mathrm{a}}\end{array}$ & $\begin{array}{c}-4,026 \\
(-2,73)^{\mathrm{a}}\end{array}$ & $\begin{array}{l}-12,819 \\
(-6,01)^{\mathrm{a}}\end{array}$ & $\begin{array}{c}-9,509 \\
(-4,52)^{\mathrm{a}}\end{array}$ \\
\hline YET & $\begin{array}{c}0,392 \\
(15,25)^{\mathrm{a}}\end{array}$ & $\begin{array}{c}0,373 \\
(13,14)^{\mathrm{a}}\end{array}$ & $\begin{array}{c}0,386 \\
(13,74)^{\mathrm{a}}\end{array}$ & $\begin{array}{c}0,379 \\
(14,15)^{\mathrm{a}}\end{array}$ & $\begin{array}{c}0,411 \\
(10,94)^{\mathrm{a}}\end{array}$ \\
\hline BUY & & $\begin{array}{c}-0,117 \\
(-2,23)^{b}\end{array}$ & $\begin{array}{c}-0,129 \\
(-2,70)^{\mathrm{a}}\end{array}$ & $\begin{array}{c}-0,244 \\
(-5,96)^{\mathrm{a}}\end{array}$ & $\begin{array}{c}-0,224 \\
(-5,63)^{\mathrm{a}}\end{array}$ \\
\hline REDK & & & $\begin{array}{c}-0,031 \\
(-1,87)^{\mathrm{c}}\end{array}$ & $\begin{array}{c}-0,062 \\
(-4,31)^{\mathrm{a}}\end{array}$ & $\begin{array}{c}-0,061 \\
(-4,22)^{\mathrm{a}}\end{array}$ \\
\hline TAS & & & & $\begin{array}{c}0,506 \\
(9,06)^{\mathrm{a}}\end{array}$ & $\begin{array}{c}0,492 \\
(8,52)^{\mathrm{a}}\end{array}$ \\
\hline EDA & & & & & $\begin{array}{c}-0,079 \\
(-6,33)^{\mathrm{a}}\end{array}$ \\
\hline $\mathrm{R}^{2}$ & 0,769 & 0,772 & 0,775 & 0,781 & 0,799 \\
\hline F testi & 56,55 & 55,43 & 54,53 & 54,61 & 49,20 \\
\hline \multicolumn{6}{|c|}{ Model Seçimi } \\
\hline F Testi & $\begin{array}{l}55,04 \\
{[0,00]}\end{array}$ & $\begin{array}{l}51,89 \\
{[0,00]}\end{array}$ & $\begin{array}{l}50,73 \\
{[0,00]}\end{array}$ & $\begin{array}{l}32,20 \\
{[0,00]}\end{array}$ & $\begin{array}{l}30,06 \\
{[0,00]}\end{array}$ \\
\hline LM Testi & $\begin{array}{l}135,71 \\
{[0,00]}\end{array}$ & $\begin{array}{l}139,69 \\
{[0,00]}\end{array}$ & $\begin{array}{l}124,40 \\
{[0,00]}\end{array}$ & $\begin{array}{l}42,67 \\
{[0,00]}\end{array}$ & $\begin{array}{l}39,50 \\
{[0,00]}\end{array}$ \\
\hline $\begin{array}{l}\text { Hausman } \\
\text { Sinaması }\end{array}$ & $\begin{array}{l}23,03 \\
{[0,00]}\end{array}$ & $\begin{array}{c}18,52 \\
{[0,00]}\end{array}$ & $\begin{array}{l}23,63 \\
{[0,00]}\end{array}$ & $\begin{array}{l}54,38 \\
{[0,00]}\end{array}$ & $\begin{array}{l}63,21 \\
{[0,00]}\end{array}$ \\
\hline
\end{tabular}

${ }^{\text {a }},{ }^{b} \mathrm{ve}^{\mathrm{c}}$ işaretleri sırasılyla $\% 1, \% 5$ ve $\% 10$ düzeyinde istatistiksel olarak anlamlılığı göstermektedir. Parantez içindeki değerler, katsayılara ilişkin t istatistiklerini gösterirken köşeli parantez içindeki değerler testlere ilişkin anlamlılık düzeylerini göstermektedir.

FE modele göre tahmin edilen 5 numaralı modelde YET değişkenine ait katsayı pozitif ve istatistiksel olarak \%1 düzeyinde anlamlıdır. YET değişkenindeki 1 birimlik artış $\mathrm{CD}$ değişkeninde 0,411 birim artışa neden olmaktadır. $\mathrm{Bu}$ bulgu, beklentilere uygun bir şekilde yenilenebilir enerji tüketimindeki oransal artışın cari açığı giderici etkide bulunduğunu göstermektedir.

Tablo 2'deki (5) numaralı modelde yer alan diğer değişkenler, cari dengeyi belirleyen makroekonomik değişkenlerdir. İlk olarak BUY değişkenine ait katsayının işareti tüm modellerde negatif ve istatistiksel olarak \%1 düzeyinde anlamlıdır. BUY değişkenindeki 1 birimlik artış, CD değişkeninde 0,224 azalışa neden olmaktadır. Beklentilere uygun olan bu bulgu, ekonomik büyümenin arttığ 1 
dönemlerde cari açığın giderek arttığını göstermektedir. İkinci makroekonomik değişken olan REDK değişkenine ait katsayının işareti negatif ve istatistiksel olarak $\% 1$ düzeyinde anlamlıdır. REDK değişkenindeki 1 birimlik artış 0,061 azalışa neden olmaktadır. Bu bulgu, reel efektif döviz kurundaki artışların cari açığı artırdığını göstermektedir ve beklentilere uygundur. Son makroekonomik değişken olan TAS değişkenine ait katsayının işareti pozitif ve istatistiksel olarak \%1 düzeyinde anlamlıdır. TAS değişkenindeki 1 birimlik artış CD değişkeninde 0,492 artışa neden olmaktadır. Beklentilere uygun olan bu bulgu, tasarruf oranındaki artışların cari açığı azaltıcı etkisinin olduğunu ifade etmektedir.

Modelde yer alan enerjiyle ilgili bir diğer değişken EDA değişkenidir. Model 5'te yer alan EDA değişkeninin katsayısı negatif ve istatistiksel olarak \%1 düzeyinde anlamlıdır. EDA değişkenindeki bir birimlik artış CD değişkeninde 0,079 birim azalışa neden olmaktadır. Bir başka deyişle enerji tüketimi içinde enerji ithalatının payı arttıkça cari açık giderek artmaktadır. Bu bulgu da beklentilere uygundur ve YET değişkenine ait değişkenden elde edilen sonucu destekler niteliktedir.

Son olarak Tablo 5 'te yer alan beş farklı modelde de yer alan YET değişkenine ait katsayının pozitif ve istatistiksel olarak \%1 düzeyinde anlamlı olduğunu vurgulamak gerekir. Bu bulgu, yenilenebilir enerji tüketimindeki artışın cari açığı gidermede önemli bir etkisinin olduğunu göstermektedir.

\section{SONUÇ}

Çalışmanın örneklemini oluşturan Avrupa Birliği ülkelerinin çoğunluğunda ve Türkiye ekonomisinde enerjide dışa bağımlılık oranı yüksektir. Enerji ticaret dengesindeki açık nedeniyle bu ülkeler, aynı zamanda cari açık sorunu yaşamaktadır. $\mathrm{Bu}$ noktadan hareketle çalışmada yenilenebilir enerji tüketiminin cari denge üzerindeki etkisini incelemek amaciyla panel veri yöntemine dayalı modeller tahmin edilmiştir. Modeller, örneklemdeki ülkelerin 1998-2015 dönemine ilişkin verisini içermektedir. Dönemi belirleyen en önemli kısıt verilerin ulaşılabilirliğidir. Bir diğer nokta ise çok sayıda ülkenin örnekleme dahil olmasına önem verilmiş olmasıdır.

Çalışmanın sonuçları, belirtilen dönemde Avrupa Birliği ve Türkiye'de yenilenebilir enerji tüketimindeki artışların, cari denge üzerinde pozitif etkiye sahip olduğunu göstermektedir. $\mathrm{Bu}$ sonuç, cari açık sorunu yaşayan ülkelerde yenilenebilir enerji üretimine yapılan yatırımların cari açık sorununu gidermede etkili olduğunu gösteren ampirik bir kanıttır. Bu etkiyi ortaya çıkartan en önemli kanal, enerjide dışa bağımlılık üzerinden gerçekleşmektedir. Yenilenebilir enerji tüketimi artan ülkelerin enerjide dışa bağımlılığ 1 azalmaktadır. Yenilenebilir enerjinin cari açık üzerine etkisini ortaya koyan ikinci kanal rekabet üzerinden gerçekleşebilir. Yerli ve tükenmeyen kaynaklarla üretilen yenilenebilir enerji üretiminin artması, enerjide dışa bağımlılığı düşürürken enerji sektöründeki riskleri/belirsizlikleri ve maliyeti uzun vadede azaltarak bir ülkenin rekabet üstünlüğü sağlamasına neden olmaktadır.

$\mathrm{Bu}$ sonuçlardan hareketle Avrupa Birliği ve özellikle Türkiye'de yenilenebilir enerji konusunda var olan farkındalığın artırılması gerekir. Bununla 
birlikte enerjide dışa bağımlı ülkelerde yenilenebilir enerji kaynakları, ithalatın ikamesi olduğu için enerji politikaları belirlenirken yenilenebilir enerjiye azami derecede önem verilmelidir. Ayrıca çevresel etkileri en aza indirilmiş ekonomik büyümeyi artırmak için daha fazla yenilenebilir enerji kullanımı teşvik edilmelidir. Son olarak yenilenebilir enerji alanında teknoloji transferini artırmak için bu sektördeki ticaretin artırılması uzun vadede yenilenebilir enerji tüketimini artırmaya katkıda bulunmaktadır.

\section{KAYNAKÇA}

Apergis, N.; Danuletiu, D. C.; (2014). Renewable Energy and Economic Growth: Evidence from the Sign of Panel Long-Run Causality, International Journal of Energy Economics and Policy, 4(4): 578-587.

Apergis, N.; Payne, J. E. (2010). Renewable energy consumption and economic growth: Evidence from a panel of OECD countries, Energy Policy, 38(1): 656-660.

Arellano, M. (2003). Panel Data Econometrics, Oxford: Oxford University Press.

Baltagi, B. H. (2005). Econometric Analysis of Panel Data, Third Edition, West Sussex: John Wiley $\&$ Sons.

Bhattacharya, M.; Paramati, S.R.; Ozturk, I.; Bhattacharya, S. (2016). The effect of renewable energy consumption on economic growth: Evidence from top 38 countries, Applied Energy, 162:733741.

Bento, J. P. C.; Moutinho, V. (2016). CO2 emissions, non-renewable and renewable electricity production, economic growth,and international trade in Italy, Renewable and Sustainable Energy Reviews, 55:142-155.

Bölük, G. (2013). Renewable Energy: Policy Issues and Economic Implications in Turkey, International Journal of Energy Economics and Policy, 3(2):153-167.

Bölük, G.; Mert, M. (2014). Fossil \& renewable energy consumption, GHGs (greenhouse gases) and economic growth: Evidence from a panel of EU (European Union) countries, Energy, 74:439446.

Calderon, C.A., Chong, A., \& Norman, L.V. (2002). "Determinants of Current Account Deficits in Developing Countries", Contributions to Macroeconomics, 2 (1), 1-31.

Çağlayan-Akay, E.; Abdieva, R.; Oskonbaeva, Z. (2015). Yenilenebilir Enerji Tüketimi, İktisadi Büyüme ve Karbondioksit Emisyonu Arasındaki Nedensel İlişki: Orta Doğu ve Kuzey Afrika Ülkeleri Örneği, International Conference on Eurasian Economies, 9-11 September 2015, Kazan, Russia.

Çalışkan, Ş. (2009). Türkiye'nin Enerjide Dışa Bağımlılık Ve Enerji Arz Güvenliği Sorunu, Dumlupinar Üni. Sosyal Bilimler Dergisi, 25:297-310.

European Commission (2013). Member States' Energy Dependence: An Indicator-Based Assessment, Economic and Financial Affairs, Occasional Papers 145.

Fang, Y. (2011). Economic welfare impacts from renewable energy consumption: The China experience, Renewable and Sustainable Energy Reviews, 15(9):5120-5128.

Freund, C. (2005), "Current account adjustment in industrial countries", Journal of International Money and Finance, 24: 1278-1298

Greene, W. H. (2012). Econometric Analysis, 7th Edition , New Jersey: Prentice-Hall International Inc.

Hogan, L.; Curtotti, R.; Austin, A. (2017). APEC Energy Security and Sustainable Development Through Efficiency and Diversity, Eighth Meeting of APEC Energy Ministers, May 2007, Darwin.

IEA (2017). Key World Energy Statistics 2017.

Jebli, M.B.; Youssef, S. B. (2015). Output, renewable and non-renewable energy consumption and international trade: Evidence from a panel of 69 countries, Renewable Energy, 83:799-808.

Kennedy, P. (2005). Ekonometri Kılavuzu, Beşinci Baskı, (Çev: M. Sarımeşeli ve Ş. Açıkgöz), Ankara: Gazi Kitabevi. 
Lehr, U.; Lutz, C.; Edler, D. (2012). "Green jobs? Economic impacts of renewable energy in Germany”, Energy Policy, 47:358-364.

Levin, A., Lin, C.F.; Chu, C.S.J. (2002), Unit Root Tests in Panel Data: Asymptotic and Finite Sample Properties, Journal of Econometrics, 108:1-24.

Menegaki, A.N. (2011). Growth and renewable energy in Europe: A random effect model with evidence for neutrality hypothesis, Energy Economics, 33:257-263.

Murat, S.; Hobikoğlu, E. H.; Dalyanc1, L., (2014). Structure and Sustainability of Current Account Deficit in Turkish Economy, Procedia - Social and Behavioral Sciences, 150:977-984.

Öztürk, İ. (2014). Energy Dependency and Security: The Role of Efficiency and Renewable Energy Sources, International Growth Center (IGC), Working Paper No: E-37113PAK-1.

Pascual, C.; Elkind, J. (2010) Introduction, Energy Security: Economics, Politics, Strategies and Implications, Edts.: C. Pascual ve J. Elkind, Washington: Brookings Institutions Press, p. 1-6

Sadorsky, P. (2009). Renewable energy consumption and income in emerging economies, Energy Policy, 37(10):4021-4028.

Salim, R. A.; Rafiq, S. (2012). Why do some emerging economies proactively accelerate the adoption of renewable energy?, Energy Economics, 34(4):1051-1057.

Stern, D. I. (2004). Economic Growth and Energy, Encyclopedia of Energy, Edit.: Cutler Cleveland, Elsevier Inc., Vol:2, p: 35-51

Tiwari, A. K. (2011). A structural VAR analysis of renewable energy consumption, real GDP and CO2 emissions: Evidence from India, Economics Bulletin, 31(2):1793-1806.

Umbach, F. (2010). Global energy security and the implications for the EU, Energy Policy, 38(3):1229-1240.

UNESCAP (2008). Energy Security and Sustainable Development in Asia and the Pacific.

US Energy Information Administration (2017). International Energy Outlook 2017.

Uz, Idil (2010), "Determinants of Current Account: The Relation Between Internal and External Balances in Turkey", Applied Econometrics and International Development, Vol. 10-2

Vaona, A. (2016). The effect of renewable energy generation on import demand, Renewable Energy, 86:354-359.

Wooldridge, J.M. (2002). Econometric Analysis of Cross Section and Panel Data, Cambridge: MIT Press.

Zhang, X.; Ruoshui, W.; Molin, H.; Martinot, E. (2010). A study of the role played by renewable energies in China's sustainable energy supply, Energy, 35(11):4392-4399.

Ek 1: Tanımlayıcı İstatistikler

\begin{tabular}{|l|c|c|c|c|c|c|}
\hline & CD & YET & BUY & DK & TAS & EDA \\
\hline Ortalama & $-1,597$ & 14,948 & 2,493 & 96,512 & 24,077 & 52,133 \\
\hline Medyan & $-1,489$ & 11,397 & 2,636 & 98,790 & 23,639 & 55,769 \\
\hline Maksimum & 11,943 & 52,300 & 25,557 & 130,670 & 54,283 & 98,290 \\
\hline Minimum & $-25,548$ & 0,872 & $-14,814$ & 53,660 & 8,330 & $-65,694$ \\
\hline Standart Hata & 5,709 & 11,162 & 3,746 & 9,838 & 7,735 & 29,249 \\
\hline Gözlem Say1s1 & 504 & 504 & 504 & 504 & 504 & 504 \\
\hline
\end{tabular}

Ek 2: Korelasyon Matrisi

\begin{tabular}{|c|c|c|c|c|c|c|}
\hline & CD & YET & BUY & DK & TAS & EDA \\
\hline CD & 1 & & & & & \\
\hline YET & 0,063 & 1 & & & & \\
\hline BUY & $-0,200$ & $-0,078$ & 1 & & & \\
\hline DK & 0,219 & 0,095 & $-0,248$ & 1 & & \\
\hline TAS & 0,559 & $-0,132$ & 0,204 & 0,008 & 1 & \\
\hline EDA & $-0,079$ & $-0,141$ & 0,043 & $-0,131$ & 0,151 & 1 \\
\hline
\end{tabular}




\section{SUMMARY}

This study investigates whether renewable energy has an impact on current account balances. It is assumed that renewable energy consumption affects the current account balance positively because renewable energy is a domestic resource, thus prevents energy imports. Increasing renewable energy consumption is important for an economy in terms of increasing energy supply security and reducing energy dependency. The high level of energy dependence causes the current account deficit as a main macroeconomic problem. Energy import is the most important reason for the deficit in the EU and Turkey. In these countries that do not have fossil fuels, renewable energy sources are the most important resource to solve this problem.

Panel data method is used in this study. The fixed effects and random effects models are implemented for the 27 European Union countries (excluding Malta) and Turkey by using data from 1998 to 2015. In this survey, the dependent variable is the current account balance and the independent variables are renewable energy consumption (percentage of total final energy consumption), economic growth, real effective exchange rate, gross domestic savings (percentage of GDP), energy imports (percentage of energy use).

When analyzing the results of five different models designed for the purpose of this study, model-5 is interpreted because of the statistically significant coefficients. The coefficient of renewable energy consumption is positive and statistically significant at $1 \%$ level in five different models. This finding suggests that the increase in renewable energy consumption is effective in reducing the current account deficit. Also, the coefficient of the energy import is negative and statistically significant at 5\% level. According to these results which are consistent with the expectations, current account deficit shows an increase when the ratio of imports in energy consumption increases in an economy.

The results of this study shows that the increase in the renewable energy consumption has a positive effect on the current account balance in the European Union and Turkey. This result is an empirical evidence that investments in renewable energy production are effective to reduce the current account deficit in these countries. High renewable energy consuming countries become less dependent on outsourcing. According to these results, The European Union and Turkey should enhance the awareness about the renewable energy production. Countries with high energy dependence should emphasize the importance of renewable energy sources to substitute imports while determining energy policies. In addition, the usage of more renewable energy sources encourages economic growth with the lowest environmental impacts. Finally, trade in renewable energy sector contributes to improving technology transfer in the sector. Thus, renewable energy production and consumption can be accelerated in an economy. These issues need to be taken into account when creating energy policies. 